\title{
An Assessment of Sexually Transmitted Infection Management at the Primary Health Care Level in a Local Government in Northern Nigeria
}

\author{
${ }^{*}$ A.T. Olayinka ${ }^{1}$ and A. U. Shehu ${ }^{2}$ \\ ${ }^{1}$ Department of Medical Microbiology, Ahmadu Bello University, Zaria. ${ }^{2}$ Department of Community Medicine, Ahmadu Bello University, Zaria.
}

\section{A B STRACT}

Background: The control of Sexually Transmitted Infections (STIs) is an important strategy in reproductive health and HIVIAIDS control. It should be such that comprehensive management of patients with STIs is available at the primary health care level. This study was to assess the quality of STI care at the primary health care level in Zaria. Method: It was a descriptive cross-sectional study in which a three-part structured questionnaire was administered to all staff who provided clinical services to patients seeking STI services in the 28 operational health centres in the local government area and these facilities were also assessed using a checklist. Results: Over half of the respondents are females (54.5\%), while the modal age group was 35-39years (36.4\%). Most of the staff providing clinical including STI services were Senior Community Health Extension Workers (SCHEWS) $(72.7 \%)$ with only $5(9.1 \%)$ nurses/midwives and $2(3.5 \%)$ being Community Health Officers (CHOs). There were training gaps identified with only $16.3 \%$ trained on STI counseling only; the $3.6 \%$ trained on syndromic management were the $\mathrm{CHOs}$ who had no knowledge of the $4 \mathrm{Cs}$ of syndromic management. While counseling of patients was routinely done by $92.7 \%$ of respondents and $70.9 \%$ promoted the use of condoms; assessment of attitude to STIs showed that $70.9 \%$ of respondents felt that STIs are as a result of promiscuity, $78.2 \%$ believed that condoms would encourage promiscuity and $45.5 \%$ felt religion is against the use of condoms. However, $92.7 \%$ are of the opinion that condom use is protective against STIs. Many of the respondents (81.8\%) support that all STI patients be screened for HIV; while $23.6 \%$ support the screening of spouses for STIs. Assessment of facilities available at the health centres show that none was adequately equipped for the syndromic management of STls. No centre had the syndromic management manual or chart; none had the STI-01 or -02 reporting forms. Only 39.3\% had drug dispensing sections. Conclusion: Primary prevention of STI should be an integral part of the PHC package; conscious effort should be made to involve the PHC level in the surveillance and treatment of STls by proper training and provision of pertinent materials.

Key words:

\section{INTRODUCTION}

Sexually Transmitted Infections (STIs) are reproductive tract Infections (RTIs) that are transmitted by sexual means. STIs continue to be a serious public health problem all over the world especially in sub-Saharan Africa. ${ }^{1}$

Curable STIs represent a large burden of disease worldwide with an annual incidence of about 333 million cases. It is believed that $86 \%$ of the world's burden is among the

Address for correspondence:

Phone No.: +234(0)803 7013141

E-mail: debolaola@yahoo.com

DOI: 10.5530/ijmedph.2.2011.16 poorest nations of the world, many of which are found in sub- Saharan Africa. ${ }^{2,3,4}$

The control of STIs is seen as an important reproductive health strategy due to its short and long term complications in obstetric and neonatal matters. Its control is also a key strategy in reducing the spread of HIV which is presently a ravaging epidemic especially in sub - Saharan Africa. Not only is the prevention and management of STIs an important public health concern in itself, but also the presence of some STIs enhances the transmission of HIV; and STI prevention and management has been shown to be effective in reducing HIV transmission. ${ }^{4,5,6}$

STIs also carry the potential risks of serious complications including fetal wastage, stillbirths, infertility, ectopic pregnancy, anogenital cancer, premature death, as well as 
severe congenital neonatal and infant infections. Syphilis alone, when present during pregnancy, results in fetal loss in a third of cases, and half the surviving infants suffer congenital disability. ${ }^{13}$

- a reduction of $50 \%$ in the prevalence of symptomatic urethritis in men

- a significant reduction in the prevalence of serological syphilis

- a $38 \%$ reduction in HIV incidence. ${ }^{6,37.39}$

Syndromic diagnosis is very simple and can be used by any trained health care provider. It is an important advantage that other service providers, in addition to doctors, can use the syndromic approach to make a diagnosis. A streamlined diagnosis and treatment process also allows health workers more time to offer education for behaviour change.

STI management at the primary health care level is very important since this is the first level of health care which should meet the most important needs of the people. It has also been found out that one third of women and onefifth of men do not receive appropriate treatment for their STDs at this level in spite of excellent provision of drugs. And so emphasis should be given on training the health care providers. ${ }^{17,18}$ The need to identify and manage STIs at the primary health facility cannot be overemphasized. They are the $1^{\text {st }}$ line of contact at the community level.

Primary health care on the whole should be an integrated approach of promotive, preventive and curative services for both the individual and the community. Thus the aim of the study was to assess the quality of STI care by looking mainly at the inputs - the infrastructure and human resources.

\section{METHODOLOGY}

The study was a cross-sectional descriptive study, it was a total population sample, the population concerned were the health workers who provided clinical service to patients in the 28 functional primary health care centres in the Local Government Area.

A 3 part semi-structured questionnaire was administered to all relevant staff in the facilities, The first part looked at socio-demographic variables of the respondents, the second part sought to obtain information on the attitude, knowledge usual practice and training background of the health workers as relates to STIs while the third part sought to identify referral networks.

Facilities were assessed using a checklist adapted from the recommendations for basic infrastructure, equipment and personnel for STI management as contained in the "Syndromic Management of STIs Manual for Health Workers" by the National AIDS and STD Control Programme of the Federal ministry of Health, Abuja, $2^{\text {nd }}$ Edition 2001. This checklist assessed the following areas in the facility The consulting/examination room, available equipments and materials, facility records and the pharmacy or dispensary.

Data was collected by trained assistants while the facilities were assessed by the researcher. Data was analyzed thematically both manually and using the Microsoft Excel spreadsheet and statistical package for social sciences (SPSS ${ }^{\circledR}$ 13.0 for Windows) software.

\section{RESULTS}

A total of fifty-five questionnaires were administered to the various relevant health workers of the Zaria local government area. All twenty-eight of the functional health facilities were also assessed.

The socio-demographic characteristics of the respondents showed that majority of the respondents were female $30(54.5 \%)$, and the modal age-group was 35-39 years (36.4\%), while the mean age was 36.76 . The majority of the staff were SCHEWS constituting $72.7 \%$ of the respondents, there were $5(9.1 \%)$ nurses/midwives while only $2(3.5 \%)$ are Community health officers.

Their years of practice ranged from one year to twenty-nine years. Mean number of years in service is $12.76 \mathrm{yrs}$ and most of them (89.1\%) have spent less than five years in their current places of work. The maximum number of years spent so far by any of the respondents at the health centre is 20 years.

\begin{tabular}{lcc}
\multicolumn{1}{c}{ Table 1: Available facilities at the health centres } \\
\hline \multicolumn{1}{c}{ Facilities } & Present & Percentage \\
\hline Enclosed Examination room & 6 & 21.4 \\
Examination couch & 10 & 35.7 \\
Screen & 13 & 46.4 \\
Latex gloves & 17 & 60.7 \\
Vaginal speculum & 6 & 21.4 \\
Functioning autoclave & 3 & 10.7 \\
Bleach or hypochlorite solution & 7 & 25.0 \\
Good or adequate lighting & 10 & 35.7 \\
Presence of syndromic & 0 & 0.0 \\
management chart & & \\
Presence of syndromic & 0 & 0.0 \\
management manual & & \\
Presence of referral forms & 6 & 17.9 \\
Presence of STI - 01 form & 0 & 0.0 \\
Presence of STI - 02 form & 0 & 0.0 \\
Presence of patient records & 13 & 46.4 \\
Presence of pharmacy & 11 & 39.3 \\
or dispensary unit & & \\
\hline
\end{tabular}


In assessing their level of awareness of STIs and attitude to those with STIs $70.9 \%$ of the respondents felt that STIs are as a result of promiscuity while $78.2 \%$ also felt that the use of condoms would encourage or promote promiscuity. Twenty five $9(45.5 \%)$ of the respondents feel religion is against the use of condoms, while $11(20.0 \%)$ were undecided as to whether it is or not. As to whether all patients with STIs should be screened for HIV or not, $81.8 \%$ of the respondents were in support while $9.1 \%$ each felt they should not or were undecided. Eighty-three point six percent $(83.6 \%)$ agreed that spouses of patients should also be screened for STIs. Only 1.8\% would inform the sexual partner and advice to go for treatment, and $21.8 \%$ would blame their sexual partner for the infection.

On their knowledge about STIs, $41.8 \%$ of respondents identified STIs as a major public health problem, while majority identified the use of condoms as being protective against STIs. Ninety point nine percent knew that STIs could be transmitted by vaginal sex and $80 \%$ through anal sex. Fifty-five point five percent and $57.4 \%$ believed that STIs could be contacted from toilet seats and pit latrines respectively.

Their knowledge on the various symptoms of STIs was varied. Many, 94.5\%, 90.9\% and $89.1 \%$ identified genital discharge, pain while passing urine and genital itching as symptoms of STIs respectively; while $56.4 \%$ and $76.4 \%$ wrongly adduced fever and generalized body itching to STIs.

\begin{tabular}{lcc}
\multicolumn{3}{c}{ Table 2: Practice of respondents on STI management } \\
\hline \multicolumn{1}{c}{\begin{tabular}{c}
\multicolumn{1}{c}{ Usual practice as regards STI } \\
management
\end{tabular}} & Do [\%] & $\begin{array}{c}\text { Don't } \\
\text { [\%] }\end{array}$ \\
\hline $\begin{array}{l}\text { Counselling patients/clients on STI/HIV } \\
\text { prevention during routine clinic visits } \\
\text { Promote condom use among your }\end{array}$ & $51[92.7]$ & $4[7.3]$ \\
$\begin{array}{l}\text { patients/clients } \\
\text { Routinely screen antenatal clients/ }\end{array}$ & $39[70.9]$ & $16[29.1]$ \\
$\begin{array}{l}\text { patients for syphilis } \\
\text { Routinely examine patients with STI }\end{array}$ & $24[43.6]$ & $30[56.4]$ \\
Invite the sex partner of my STI patients & $46[80.0]$ & $11[20.0]$ \\
Refer STI patients to other facilities & $38[69.1]$ & $9[16.4]$ \\
\hline
\end{tabular}

\begin{tabular}{lcc}
$\begin{array}{l}\text { Table 3: Knowledge of transmission of STIs among } \\
\text { respondents }\end{array}$ \\
\hline \multicolumn{1}{c}{ Route of Transmission } & Frequency & Percent \\
\hline Vaginal sex & 50 & 90.9 \\
Anal sex & 44 & 80.0 \\
Oral sex & 25 & 45.5 \\
Deep kissing & 12 & 2.8 \\
Use of pit latrines & 24 & 43.6 \\
From toilet seats & 25 & 45.5 \\
Through blood transfusion & 34 & 81.8 \\
By sharing a bed with an infected & 43 & 78.2 \\
person & & \\
\hline
\end{tabular}

Out of all the respondents only $16.3 \%$ had been trained on STI counseling. Three of nine had their counseling training while in school while the rest had in-service trainings. Only 3.6\% had been trained on syndromic management of STIs. The two who said they had received training on syndromic management were the only 2 Community Health officers (CHOs) out of all the respondents.

Twenty-seven point three percent I5(27.3\%) of the respondents had heard of the term "Syndromic management" before. However, they didn't have the manual or charts to use and didn't know any of the four 4Cs of syndromic management.

On why STI patients are not examined by some respondents, $18.2 \%$ said it was due to lack of privacy in their health centres, $9.1 \%$ did not examine because of their religious beliefs.

Reasons given by respondents on why they don't invite the sex partners of their patients who have STIs were having no knowledge about it, not wishing to scatter homes and out of respect for privacy each reason given by $11.1 \%$ of the concerned respondents.

Thirty point nine percent $(30.9 \%)$ of respondents say they don't refer patients with STIs. Out of these, $29.4 \%$ of them said it's because they've never had patients with STIs and an equal number said it's because they can treat them only $5.9 \%$ said they don't refer because of lack of referral forms.

Various reasons were given for referring patients with STIs, such as due to lack of drugs, severity of case, suspected HIV infection or for effective management. Two point six percent $(2.6 \%)$ each refer either when infection persists despite treatment, or when patient demands for referral or when the standing order dictates so.

The health centres in the Zaria Local Government Area were assessed using a checklist. No centre had the syndromic management manual or chart. The STI-01 and STI-02 reporting forms were also not present in any of the health centres. Records of patient attendance were present in $46.4 \%$ of the centres while $39.3 \%$ had a drugs dispensing section.

\section{DISCUSSION}

This study on the assessment of STI management at the Primary health care level in Zaria, shed some light on the level of awareness and knowledge of Sexually Transmitted Infections (STIs) and syndromic management among primary health care workers in a part of Nigeria. It also gives an insight into the current state of Primary health 
care (PHC) facilities and their suitability for STI management using the syndromic approach.

In this study, majority $(72.7 \%)$ of the health care providers were Senior Community Health Extension Workers, with only $9.1 \%$ and $3.5 \%$ being nurse/midwives and Community Health Officers (CHOs) respectively. This type of distribution of health workers at the PHC level is similar to what was obtained in a national survey carried out in 2001 where majority of the PHC health workers were mainly Junior and Senior Community Health Extension Workers (JCHEWS and SCHEWS). ${ }^{49}$ This means that currently in Nigeria, CHEWS form the major Health care providers in the community. The question now is how many CHEWS are trained on syndromic management of STIs.

In another study it was estimated that only $18 \%$ of all doctors, $15 \%$ of nurses and about half of lab technicians and almost all the managers received training on syndromic management of reproductive tract infections. ${ }^{42}$ No mention of CHEWS were made. However the aim of syndromic case management of STIs is to enable all trained, first line health service providers diagnose an STI syndrome and treat patients on the spot without waiting for the results of time consuming and costly laboratory tests, thereby ultimately helping to prevent the further spread of STIs. ${ }^{50}$

There was some awareness on STIs among the respondents but their attitudes were divergent (Table 4). Seventy point nine percent $(70.9 \%)$ felt that STIs were as a result of promiscuity and $78.2 \%$ also felt that condom use encourages promiscuity. The attitude and beliefs of the health care provider is of importance especially with respect to issues of discrimination and stigma. A poor or negative attitude of the health worker is likely to lead to poor uptake of services being provided..$^{35}$

The role of religion in the life of the people is significant in relation to their attitude. Many $(45.5 \%)$ felt that religion is against the use of condoms while $11 \%$ were undecided as to whether it was or was not; also $78.2 \%$ considered condoms as promoting promiscuity or sexual immorality while forgetting that although condoms are useful as a protective device against STIs, they were primarily developed for birth control purposes. ${ }^{51}$ This attitude may affect the effective control of STIs if care-providers place difficulties in the way of implementation due to their reluctance to use certain methods or strategies. ${ }^{52}$ The promotion and usage of condoms for the sexually active engaged in high risk sexual behaviours remains the most effective strategy for limiting the risk of acquisition of STIs, including HIV / AIDS. Unfortunately, attitudes towards condom usage has generally been found to be rather negative. ${ }^{29,53,54}$ The general belief that condoms are not used with regular partners or within marriage has also been documented across regions by WHO. ${ }^{55}$

With the current concept of integration of services under the PHC scheme, it is worthy to note that $65.5 \%$ of the respondents disagreed with the separation of patients with STIs from other patients. Some countries have reported on successful integration of STI care with other health services such as urological, family planning, antenatal, maternal and child and family health care. ${ }^{13,56,57}$ The limitation with many of these services is that the groups at highest risk such as males of all ages, single sexually active women and sex workers are not normally reached by the conventional family planning and maternal and child health programs. ${ }^{13,57}$

Counselling in STI management has a major role especially in the promotion of an intervention that should lead to a decrease in individual high-risk sexual behaviour, encourage behavioural change promotion and ultimately lead to a reduction in the prevalence and incidence of STIs. ${ }^{62}$ Also counselling is one of the four (4)c's or components of syndromic management. ${ }^{63}$ Any visit by a patient or client should be an opportunity for both counselling and education. Out of all the respondents, only 9/55 (16.3\%) had been trained on STI counselling whether in-service or in-school. Their knowledge on syndromic management was very low; $27.3 \%$ had heard of the term syndromic management, but only $2 / 55(3.6 \%)$ had had any training in it and unfortunately they didn't know the 4Cs and had no manuals or charts that could serve as a guide

Often, service providers do not have a choice whether to attend in-service training or not, and trainers end up training service providers who do not need to know, or who are not interested in learning new skills. Wherever possible, training should be targeted towards those who will be able to use the knowledge and skills frequently and have expressed an interest in learning the skills. Assessing the learning needs of trainees can be an important first step towards improving the impact of the training.

As to the actual practice of the health workers as regards STI management, most of them $(92.7 \%)$ said they counsel patients and clients routinely on STI. The content of the counselling however could not be ascertained. Many $(70.9 \%)$ also said they promote the use of condoms.

Another factor noted was that clinics and staff were not sufficiently prepared and empowered to offer screening and treatment, these are basic necessities to provision of adequate care. ${ }^{64}$ This is in agreement with similar findings in Botswana where $60 \%$ of the clinics lacked visual and auditory privacy. ${ }^{68} \mathrm{~A}$ lack of auditory and or visual privacy during consultation has been cited as one reason why 
providers were unwilling to discuss sexual behaviour and STIs with their clients. Service providers feel that they know their clients well and frequently cited this relationship as the reason why they did not feel the need to ask about the sexual behaviour and other risk factors. As a result of not discussing these issues, they were found to have incorrect assumptions about, their clients; out of those felt by providers not to be at risk, $52-70 \%$ percent of them felt they were. ${ }^{68,69}$

The assessment of the health centres revealed a dire lack of necessary items for STI management. Some basic things such as an enclosed consulting/examination room for the purpose of privacy was lacking in $78.6 \%$ of the centres, and only $46.4 \%$ had examination screens; which means that there's no auditory or visual privacy for the patients. Even though $6(21.4 \%)$ centres had specula, only 3centres $(10.7 \%)$ had functioning autoclaves, this means that the sterility of the instruments are questionable and there is risk of iatrogenic infections especially Hepatitis B virus infection and HIV infection.

None of the facilities had either a syndromic management manual or a chart; neither were any of the STI reporting forms available. Less than half of the facilities had patient's records, such that the utilisation of the centre could not be objectively determined. None of the clinics had the national STI reporting forms 01 and 02, most of the workers were not aware that such forms were in existence. Centres can only supply quality data if expectations are realistic.

Records of attendance were present in $46.4 \%$ of the centers, most of which were incomplete nor were they up to date. Keeping of records has been said to be not just an aid to a centre but also an essential component and contribution to the disease surveillance system; which shows up trends in disease patterns and is of vital importance in the battle to control disease. ${ }^{5}$

Only $39.3 \%$ of the health centres had a drug dispensing section, but the medications relevant to STI care were lacking in most places. These go to demonstrate the inability of the centres to meet some of the basic requirements in STI management. Procaine penicillin was the most common medication available, probably because it is being used to treat other forms of infectious disease in addition to its use for the treatment of STIs. Generally drugs available were far below what it should be based on the national essential drug list for primary health care centres; and some drugs needed for STI treatment were totally absent.

Condoms were available only in 7 of the health facilities. Of these centres, only one $(3.6 \%)$ gave the condoms out free. All others sold them to the clients and patients at costs ranging from one to twenty naira per pack. The cost of these services may further reduce their utilisation.

With the absence of basic essential equipments, consumables and drugs; the expected improvement in the quality of care will not occur; and there will be little or no progress in efforts to control STIs and HIV.

The fundamental aim of Primary Health Care (PHC) is to ensure universal access to available resources in order to provide adequate coverage of the most important needs of the people and it also represents one of the major health reforms in the last century. STI management is an important need of the people which requires that it should be adequately addressed by the health service provided at all levels.

There needs to be an efficient and effective management of STIs in clinics at the primary health level if we are to combat the scourge of HIV/AIDS and bring about a reduction in the morbidity and mortality due to STIs.

Primary prevention of STI should be an integral part of the primary health care package. It is necessary to introduce the general principle of STI case management into the various medical services and monitoring the quality of medical care.

\section{REFERENCES}

1. World Health Organization. Global prevalence and Incidence of selected curable STIs: Overview and Estimates. Geneva. WHO. 2001.

2. Center for diseases Control and Prevention. Pelvic inflammatory Disease: Guidelines for prevention and management. MMWR 1991:40:1-25.

3. Sanko R, McCoy D, Gosa E, Hamelmann C, Chabikuli N, Mays A, Ramkissoon A and Hlazo J. an overview of issues on STI management and control in South Africa. Health System trust. Durban, South Africa. March 2003:1.

4. World Health Organization 30.

5. STI/HIV prevention programmes. "UNAIDS/WHO Working Group on Global HIVIAIDS/STI Surveillance, 1999.

6. Grosskurth H, Masha F, Todd J. Impact of improved treatment of STDs on HIV infection in rural Tanzania. Randomized clinical trial. Lancet, 1995; 346:530-536.

7. Shelton JD, Fuchs N. opportunities and pitfalls in integration of family planning and HIV efforts in developing countries. Public Health Reports. Jan - Feb 2004; 119:12-15.

8. Mayaud P, Ka-Gina G, Cornelisse J. Validation of a WHO algorithm with risk assessment for the clinical management of vaginal discharge in Mwanzi, Tanzania. Sex Transm Infect 1998; 74 (Suppl1): S29-33.

9. Consultations on STD Interventions for preventing HIV: What is the Evidence? Joint United Nations Programme on HIVIAIDS (UNAIDS), Geneva, Switzerland 2000.

10. Boonstra E, Lindbaek m, Klouman E, Ngoma E, Romoren M, Sundby J. Syndromic management of STDs In Botswana's primary health care: quality of care aspects. Trop Med Int Health. 2003:8(7):604-14. 
11. World Health Organisation. Primary Health Care: The Alma-Ata Declaration. World Health Organisation,1978.

12. National Primary Health Care Development Agency Abuja NEEDS Assesment Survey of Primary health Care status in Local Government Areas. April 2001.

13. WHO/CHS/HIS/99.2. UNAIDS/WHO Working Groups on Global HIVI AIDS/STI Surveillance. Guidelines for Sexually Transmitted Infections Surveillance., 1999.

14. Training module for the syndromic management of STIs. $2^{\text {nd }}$ edition. Dept of Reproductive Health and Research WHO.

15. Ejembi CL, Alti-Muazu M, Chirdan O, Ezeh HO, Sheidu S, Dahiru T. Utilization of maternal health services by rural Hausa women in Zaria environs of Northern Nigeria: has PHC made a difference? Journal of Community medicine and primary health care.2004,16;:47-54.

16. Association for Reproductive and family health in Nigeria. A comparative review of four (4) studies. AFRH., Ibadan 1996. 9-26.

17. An overview of issues on STI Management and Control in South Africa.. Sexually Transmitted Infections. R. Sonko, D. Mc Coy, E. Gosa, C. Hammelmann, N. Chabikuli, A. Moys, A. Ramkissoon and J. Hiazo. Hea;th Sysytems Trust, S. Africa. March 2003.

18. Ejembi CL, Otu A. Sexual behaviour, contraceptive practice and reproductive health outcomes among Nigerian university students Journal of Community medicine and primary health care.2004,16:8-16.

19. Nicols D, Ladipo AO, Paxman J and Otolorin EO. Sexual behaviour, contraceptive practice and reproductive health among Nigerian Adolescents. Studies in Family Plannig 1986. 17 (2):100-106.

20. Federal Ministry of health National HIVIAIDS reproductive health survey (NARHS). Federal Ministry of health, Abuja. October 2003.
21. The incidence and prevalence of STIs. Report of a WHO consultation. Treviso, Italy. 27Feb - 1Mar 2002.

22. B. N. Maggwa and I. Askew. Integrating STI/HIV Management strategies into existing maternal \& child health / family planning programs: lessons from case studies in East and Southern Africa. Africa OR/TA Project II. The Population Council, Nairobi, Kenya. June 1997.pp5-7.

23. B. N. Maggwa and I.Askew. Integration of STI Prevention and management with family planning and Antenatal clinics in Sub-Saharan Africa - What more do we need to know? Int. Family Planning Perspectives. 2002. 28 (2):77-86

24. Kamali A, Quigley M, Nakiyikgi J, Kinsman J, Kengeya-Kayendo J, Gopal R. Syndromic Management of STIs and behaviour change interventions on transmission of HIV-1 in rural Uganda: a community randomized trial. Lancet 2003. 361; 645-52.

25. Syndromic management of STIS. Manual for health Workers. National AIDS \& STD Control Programme. Federal Ministry of Health, AbujaNigeria. Editors: Abebe E.A., Olumide Y. M., Oke O., Jackson D., SaniGwarzo N., Derex-Briggs I. $2^{\text {nd }}$ edition. 2001 p10.

26. Sexually transmitted and other reproductive tract infections. A guide to essential practice. Department of Reproductive Health and Research.

27. B. N. Maggwa and I. Askew. Integrating STI/HIV Management strategies into existing maternal \& child health / family planning programs: lessons from case studies in East and Southern Africa. Africa OR/TA Project II. The Population Council, Nairobi, Kenya. June 1997.pp19.

28. Musa EO and Ejembi CL. Reasons and outcome of paediatrics referrals from first level health facilities in Sabon Gari, Zaria. North Western Nigeria. Journal of Community medicine and Primary Health Care. 2004. 16(1):10-15 